\title{
MODAL DAMPING OF FLEXURAL OSCILLATION IN SUSPENDED CABLES
}

\author{
By Hiroki YAMAGUCHI* and Yozo FUJINO**
}

\begin{abstract}
The modal damping of flexural oscillation of suspended cable models was measured and is reported in this paper. Numerical analyses of free oscillation of the cables were also made to calculate natural frequencies, normal modes and additional dynamic strains. It is found that the additional dynamic strain of each normal mode is the primary cause of modal damping and that the damping of the first in-plane symmetric mode is much larger than that of other modes around the 'crossover' point of the first and second natural frequencies. The effects of the span length, the tensile rigidity and the chord inclination are also investigated.

Keywords : cable, modal damping, experiment, flexural oscillation, additional dynamic strain
\end{abstract}

\section{INTRODUCTION}

Cables have been widely used as structural members in transmission lines, telecommunication lines, cable-stayed bridges, and suspension bridges. Severe oscillations of these cables due to wind, such as galloping and buffeting, can easily occur because of flexibility, and have been reported frequently.

In order to check the aerodynamic stability of structures, in general, their dynamic characteristics such as natural frequencies, normal modes and structural dampings, are required to be known. The structural dampings play an important role in the aerodynamic behavior. The damping of structure, however, is very difficult to estimate analytically because it is influenced by many factors including connections of members, supporting systems, masses, etc. ${ }^{1)}$ and an ordinary way to estimate the damping of whole structures is rather empirical and has been by using past experimental data.

The damping of a single cable is much simpler than the damping of a whole structure and several studies have been made about the damping of single cables $^{2) ~}{ }^{2}$. Refs. 2) 4) deal only with the first flexural modal damping of taut wire ropes with very small sag-to-span ratios, and Ref.5) is concerned with hysteresis damping of wire ropes during axial oscillation. All of these treat the material damping of ropes and no research has been reported about the damping of cable as a structure except Ramberg's on $\mathrm{e}^{6)}$ which investigated the dynamic characteristics of marine cables. The structural damping of a cable is often represented by its modal damping which is the structural damping corresponding to each normal mode. The importance of modal damping is obvious in the sense that the modal damping will be reflected in the modal selection during self-excited oscillations and in the stationary amplitude of buffeting motion. The results

* Member of JSCE, Dr. Eng., Assoc. Prof. of Foundation Eng., Saitama Univ. (Shimo-ohkubo 255, Urawa, Saitama 338)

** Member of JSCE, Ph. D., Assoc. Prof. of Eng. Res. Inst., Fac. of Eng., Univ. of Tokyo (Yayoi 2-11-16, Bunkyo-ku, Tokyo 113) 
of a wind tunnel test ${ }^{7)}$, for example, show that the galloping of a telecommunication cable was not excited in the first mode of the cable but in the second mode. This can be explained partly due to differences in modal dampings. Actually some data of modal damping of telecommunication cables $^{8)}$ shown in Table 1 indicate that the first modal damping is one order larger than dampings in other higher modes.

In what follows the modal damping characteristics of single cables during flexural oscillation are investigated through free oscillation experiments with model cables. The sag-to-span ratio is chosen as the principal parameter in testing and it is investigated how modal

Table 1 Modal Damping of Telecommunication Cable ${ }^{8)}$.

\begin{tabular}{|c|c|c|c|c|c|c|}
\hline Cable & $\begin{array}{l}\text { Weight } \\
(\mathrm{kg} / \mathrm{m})\end{array}$ & $\begin{array}{l}\text { Sag } \\
\text { ratio }\end{array}$ & $\begin{array}{l}\text { Span } \\
(\mathrm{m})\end{array}$ & Mode & $\begin{array}{l}\text { Freq. } \\
(\mathrm{Hz})(*)\end{array}$ & $\begin{array}{l}\text { Log } \\
\text { decre. }\end{array}$ \\
\hline $\begin{array}{c}0.9-100 C A \\
(65 S W)\end{array}$ & 2.04 & 0.0215 & 250 & $\begin{array}{r}\text { S1 } \\
\text { AS1 } \\
\text { S2 } \\
\text { AS2 }\end{array}$ & $\begin{array}{l}0.35(1.5) \\
0.47(2.0) \\
0.72(3.1) \\
0.96(4.1)\end{array}$ & $\begin{array}{l}0.143 \\
0.0120 \\
0.0102 \\
0.0085\end{array}$ \\
\hline $\begin{array}{c}0.9-100 C A \\
(65 S W)\end{array}$ & 2.21 & 0.0194 & 160 & $\begin{array}{r}\text { S1 } \\
\text { AS1 } \\
\text { S2 } \\
\text { AS2 }\end{array}$ & $\begin{array}{l}0.56(1.8) \\
0.63(2.0) \\
0.95(3.0) \\
1.24(3.9)\end{array}$ & $\begin{array}{l}0.202 \\
0.0126 \\
0.0098 \\
0.0072\end{array}$ \\
\hline $\begin{array}{c}0.65-100 \\
\text { FLA } \\
(45 S W)\end{array}$ & 1.37 & 0.0188 & 82 & $\begin{array}{r}\text { S1 } \\
\text { AS1 } \\
\text { S2 } \\
\text { AS2 }\end{array}$ & $\begin{array}{l}0.75(1.7) \\
0.88(2.0) \\
1.35(3.1) \\
1.79(4.1)\end{array}$ & $\begin{array}{l}0.161 \\
0.0210 \\
0.0210 \\
0.0187\end{array}$ \\
\hline
\end{tabular}

* Nondimensionalized by the 1st natural frequency of string dampings change as the sag-to-span ratio changes. In addition, the effects of span length, tensile rigidity and chord inclination on modal dampings of cable will be also discussed. Free oscillation analysis of cable is also made to calculate the additional tensions during each modal oscillation. Relation of the additional dynamic strain to modal dampings will be discussed.

It should be mentioned that the investigation of modal dampings of cable gains more importance, particularly in recent years, in view of the discussion about the so-called system-damping of cable-stayed bridges $^{9)}$ and cables used for a cable-stayed damper of suspension bridge towers during erection ${ }^{5}$.

\section{FREE OSCILLATION EXPERIMENTS WITH MODEL CABLES}

The model cables employed in the experiments are 7-wire strand ropes to which lead weights (15. $1 \mathrm{~g} /$ weight), available as sinker in the market, were attached at interval of about $9 \mathrm{~cm}$ distances in order to adjust the weights. Their model specifications are listed in Table 2. Each cable was wound with several turns around a horizontal bar-steel, which was connected rigidly to a steel rigid support, and then mounted in the support through a turnbuckle (Fig.1). The end condition of cable was accordingly considered to be completely fixed but, as is mentioned later on, it was slightly movable in the direction perpendicular to the cable axis in the case of out-of-plane motions of the short-spanned cable with small sag. The sag of cable was adjusted by the turnbuckle.

The test cable set up with required sag-to-span ratio was forced to oscillate at each natural frequency by using a dynamic jack which was connected to a point of the cable through a thread (Fig. 1). The thread was cut after stationary oscillation was attained, and the subsequent decay of free vibration was recorded. The cable was excited vertically (or transversely) in order to obtain in-plane (or out-of-plane) oscillation. The excitation point was changed such that the mode concerned was purely excited. The dynamic displacements were measured by means of the target of an electro-optical displacement follower, attached to the cable at an appropriate point (quarter-span, mid-span, etc.) ; the amplitude decay was recorded on a strip chart pen-recorder in order to compute the natural frequencies and logarithmic decrements. It was found that the

Table 2 Cable Model Specifications and Test Conditions

\begin{tabular}{|c|c|c|c|c|c|c|}
\hline Cable & $\begin{array}{l}\text { Type } \\
\left(\begin{array}{l}\text { Dia.of } \\
\text { wire }\end{array}\right)\end{array}$ & $\begin{array}{l}\text { Tensile } \\
\text { rigidity } \\
\text { EA(kg) }\end{array}$ & $\begin{array}{l}\text { Break } \\
\text { tension } \\
\mathrm{T}_{B}(\mathrm{~kg})\end{array}$ & $\begin{array}{l}\text { Weight } \\
\text { w }(\mathrm{kg} / \mathrm{m})\end{array}$ & $\begin{array}{l}\text { Span } \\
\text { length } \\
\ell(\mathrm{m})\end{array}$ & $\begin{array}{l}\text { Chord } \\
\text { incli- } \\
\text { nation } \\
\theta(\text { deg. }\end{array}$ \\
\hline CABLE1 & $\begin{array}{l}\text { SWR } 1 \times 7 \\
(0.2 \mathrm{~mm})\end{array}$ & $3.97 \times 10^{3}$ & 55 & 0.17 & 2.05 & $\frac{0}{30}$ \\
\hline CABLE2 & $\begin{array}{l}\text { SWR } 1 \times 7 \\
(0.5 \mathrm{~mm})\end{array}$ & $2.45 \times 10^{4}$ & 280 & 0.17 & $\frac{2.05}{7.35}$ & 0 \\
\hline
\end{tabular}

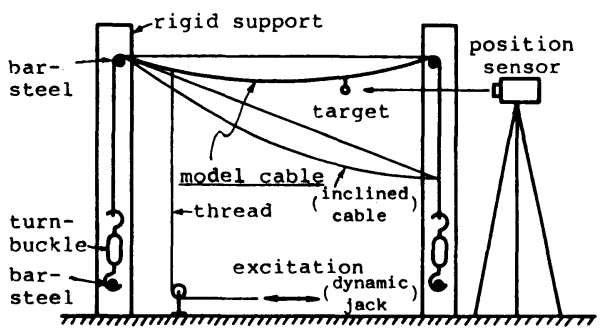

Fig. 1 Schematic diagram for experiment set-up. 
logarithmic decrements depended on the amplitude (as is mentioned in detail below), so that the damping was measured at the peak amplitude of the mode shape nearly equal to $0.24 \%$ of span length $l$ ( $5 \mathrm{~mm}$ for $l$ $=2.05 \mathrm{~m}$ and $18 \mathrm{~mm}$ for $l=7.35 \mathrm{~m})$. Logarithmic decrements for that modal amplitude are discussed in this paper. The measuring point did not always coincide with the point of peak amplitude of the mode shape and in that case the modal amplitude was calculated by using the analyzed mode shape.

In most instances the free damped oscillation of desired mode could be obtained by changing the excitation point and the initial condition, i. e., the cut timing of the excitation thread, while the coupling of in-plane and out-of-plane motions ${ }^{10)}$ occurred for certain sag-to-span ratios and the higher modes were sometimes superimposed in the desired in-plane symmetric mode owing to abrupt cutting of the thread.

\section{FREE OSCILLATION ANALYSIS BY FINITE ELEMENT METHOD}

Two kinds of analytical procedures are available to calculate the natural frequencies, normal modes and the additional tensions of suspended cables; one is Galerkin's method with the trial function of Fourier series $^{11) .12)}$ and another is the finite element method ${ }^{13)}$. Preliminary analyses were conducted in order to compare these two methods and it was found that there was no significant difference in natural frequencies, normal modes and additional dynamic strains. The finite element method was employed in this study since it can calculate nonlinear dynamic strain from the nonlinear relation between strains and displacements. We used the 3-node quadratic element with the shape functions of quadratic polynomial, and the element matrices such as the mass and elastogeometric matrices which are shown in Ref. 13) were applied. The static equilibrium configuration due to the self weight was analyzed first, and next the eigenvalue problem was solved for small oscillations about the nonlinear equilibrium position by evaluating the tangential stiffness matrix. Using the obtained mode vectors which are normalized relative to the maximum displacement value, the additional dynamic strain at the internal node of each element is then calculated by

$\Delta \varepsilon_{i}^{e}=\left\{x_{0}^{e}\right\}^{T}\left[N^{\prime}\right]^{T}\left[N^{\prime}\right]\left\{\phi_{i}^{e}\right\} A$,

where $\Delta \varepsilon_{i}^{e}$ is the dynamic strain at the internal node for the $i$-th normal mode $;\left\{x_{0}^{e}\right\}$ and $\left\{\phi_{i}^{e}\right\}$ are element components of the initial configuration vector and the $i$-th normal mode vector, respectively; $\mathrm{A}$ is the modal amplitude as was mentioned in the previous section. $\left[N^{\prime}\right]$ in Eq. (1) is the first derivative of shape function evaluated at the internal node, and for the parabolic displacement field it is written as

$$
\left[N^{\prime}\right]=\frac{1}{2}\left[\begin{array}{rrrrrrrrr}
-1 & 0 & 0 & 0 & 0 & 0 & 1 & 0 & 0 \\
0 & -1 & 0 & 0 & 0 & 0 & 0 & 1 & 0 \\
0 & 0 & -1 & 0 & 0 & 0 & 0 & 0 & 1
\end{array}\right]
$$

Eq. (1) is derived by linearizing the elemental equation of nonlinear strain-displacement relation;

$$
\varepsilon^{e}=\frac{1}{2}\left(\left\{x^{e}\right\}^{T}\left[N^{\prime}\right]^{T}\left[N^{\prime}\right]\left\{x^{e}\right\}-1\right),
$$

where $\left\{x^{e}\right\}$ is the position vector, i. e., configuration vector in the deformed geometry and $\varepsilon^{e}$ is the associated Lagrangian strain. We can use Eq. (4) based on Eq. (3) in order to evaluate the additional dynamic strain for each normal mode from the non-linear strain-displacement relation.

$$
\Delta \varepsilon_{i}^{e}=\frac{1}{2}\left(\left\{x_{0}^{e}+A \phi_{i}^{e}\right\}^{T}\left[N^{\prime}\right]^{T}\left[N^{\prime}\right]\left\{x_{0}^{e}+A \phi_{i}^{e}\right\}-1\right)-\frac{1}{2}\left(\left\{x_{0}^{e}\right\}^{T}\left[N^{\prime}\right]^{T}\left[N^{\prime}\right]\left\{x_{0}^{e}\right\}-1\right),
$$

where the second term in the right side signifies the initial strain. The accuracy of analysis based on the nonlinear evaluation of dynamic strain, Eq. (4), however, is difficult to check, so the additional strain calculated mainly from Eq. (1) is discussed in this paper. The nonlinear equation (4) is adopted only for one case for reference.

The additional dynamic strain, which has a different value for each internal node of element, is obtained as a dynamic strain mode, and the root mean square of dynamic strains $\Delta \varepsilon$ is taken as the representative value for each normal mode. The numbers of elements and nodes in the numerical analysis were taken to be 21 and 43 , respectively. 


\section{RESULTS AND DISCUSSIONS}

(1) Characteristics of natural frequencies, normal modes and modal dampings

Fig. 2 shows the relation between natural frequency $f$ and sag-to-span ratio $\gamma$ for $2.05 \mathrm{~m}$ span cable. The experimentally measured values are plotted with theoretical curves for the in-plane first symmetric mode (S 1), the in-plane first asymmetric mode (AS 1) and the out-of-plane first symmetric mode (OUT $\mathrm{S} 1$ ). Fig. 2 indicates that the experimental results fairly coincide with the theoretical ones and high accuracy of the experiment is confirmed.

A distinct feature in Fig. 2 is the in-plane first symmetric mode, that is, one can recognize the existence of so-called modal crossovers ${ }^{11)}$ in certain region of sag-to-span ratio where the mode shape changes into the higher symmetric mode with two additional nodes while increasing the natural frequency. The experimentally measured values of corresponding modal damping represented by log decrements are shown in Fig. 3 for the model cable, CABLE 2. It can be seen in Fig. 3 that the damping of in-plane first symmetric mode is larger than other modal damping in the modal transition region, especially for the sag-to-span ratio around the modal crossover point. The modal dampings of telecommunication cables shown in Table 1 are those for the sag-to-span ratios close to the first modal crossover, judging from the corresponding natural frequencies. For this reason, it is quite natural to understand the fact that the first modal dampings are one order larger than other modal dampings in Table 1. It can be also recognized in Fig. 3 that the dampings for the in-plane first asymmetric mode and for the out-of-plane first symmetric mode have small and almost constant value over a wide range of the sag-to-span ratio.

Fig. 4 and Fig. 5 are for $7.35 \mathrm{~m}$ span cable of CABLE 2. In these figures the results for the in-plane second symmetric (S 2), second asymmetric (AS 2) and out-of-plane first asymmetric (OUT AS 1) modes are also plotted. The characteristic of the modal damping does not change qualitatively when the span length of cable becomes long. The modal crossover of the in-plane second symmetric mode occurs in the sag-to-span ratio larger than that of the first modal crossover (Fig. 4) and the corresponding modal dampings have a peak at larger sag-to-span ratio (Fig.5). One can also see the tendency that the out-of-plane modal dampings are somewhat smaller than the in-plane asymmetric modal dampings and that those dampings become large when the sag-to-span ratio increases.

( 2 ) Dependence of modal damping on amplitude

The dependence of each modal damping on amplitude is shown in Fig. 6, where the results for the $2.05 \mathrm{~m}$ span cable of CABLE 2 with three sag-to-span ratios $(\gamma=0.02,0.03$ and 0.05$)$ are plotted. As can be

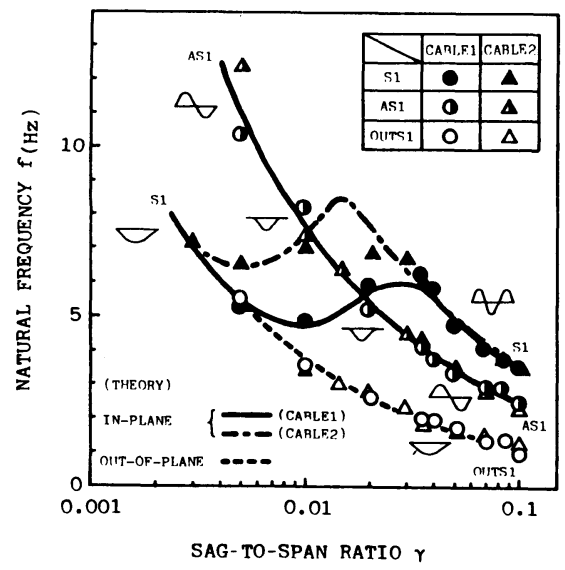

Fig. 2 Natural frequency versus sag-to-span ratio $(l=2.05 \mathrm{~m})$.

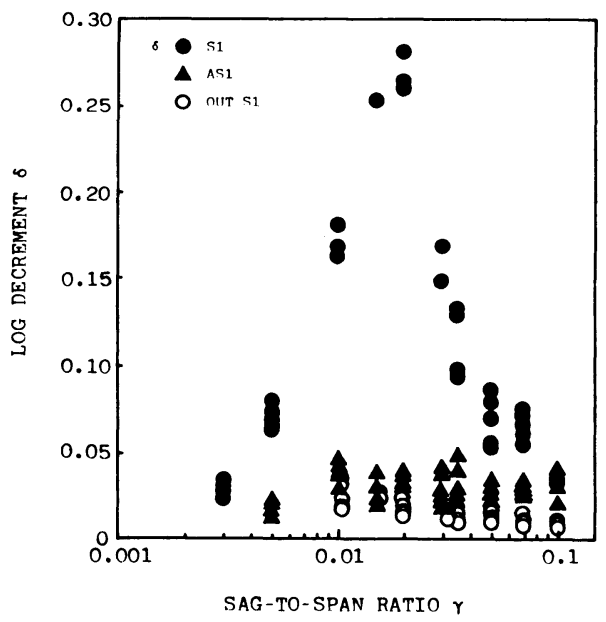

Fig. 3 Log decrement versus sag-to-span ratio $($ CABLE $2, l=2.05 \mathrm{~m}$ ). 


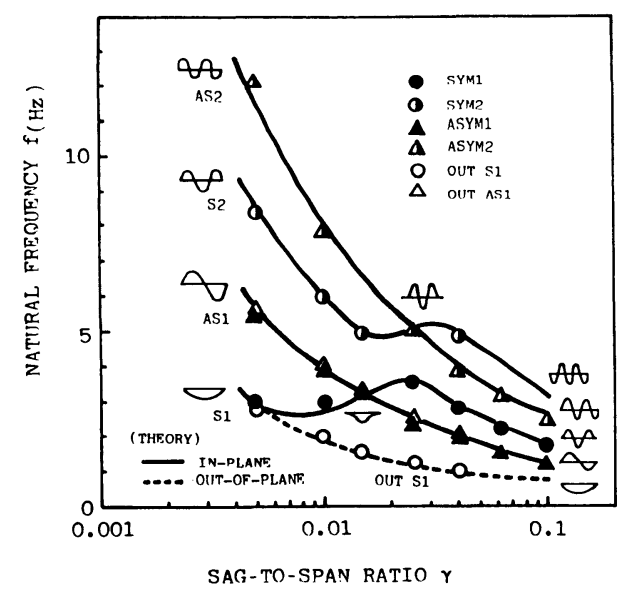

Fig. 4 Natural frequency versus sag-to-span ratio $(l=7.35 \mathrm{~m})$.

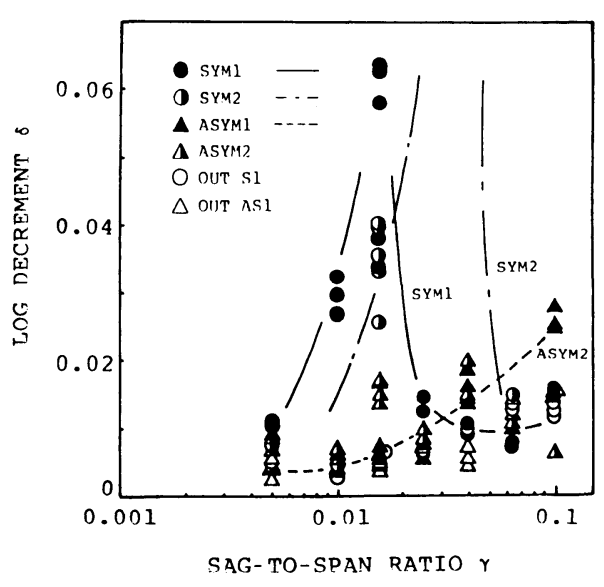

Fig. 5 Log decrement versus sag-to-span ratio $(l=7.35 \mathrm{~m})$.

seen from Fig. 6, every modal damping becomes smaller for the smaller amplitude and the dependence on amplitude is remarkable for large dampings; the dependence of the in-plane first symmetric modal dampings on amplitude is outstanding for $\gamma=0.02$ but is relatively low for $\gamma=0.05$. The in-plane asymmetric and out-of-plane modal dampings, which take very small values, hardly depend upon the amplitude.

\section{(3) Relationship between additional dynamic strain and modal damping}

The internal damping due to the hysteresis energy is expected to be one primary source of cable damping. This hysteresis energy is related to the additional dynamic strain; the experimental study ${ }^{5}$ on damping of wire ropes concludes that the hysteresis energy is proportional to square of dynamic strain. Fig. 7 is the plots of the experimentally measured values of the in-plane first symmetric modal damping taken from Fig. 3 and Fig. 5, and of the analytically calculated value of corresponding dynamic strain, versus the sag-to-span ratio. It can be seen from Fig. 7 that the change of modal damping with respect to the sag-to-span ratio is very similar to that of dynamic strain. The calculated dynamic strain of the first asymmetric mode, which is also shown in Fig. 7, is very small in comparison with that of the first symmetric mode, and the dynamic strain of out-of-plane mode is zero in the linear theory. This accounts

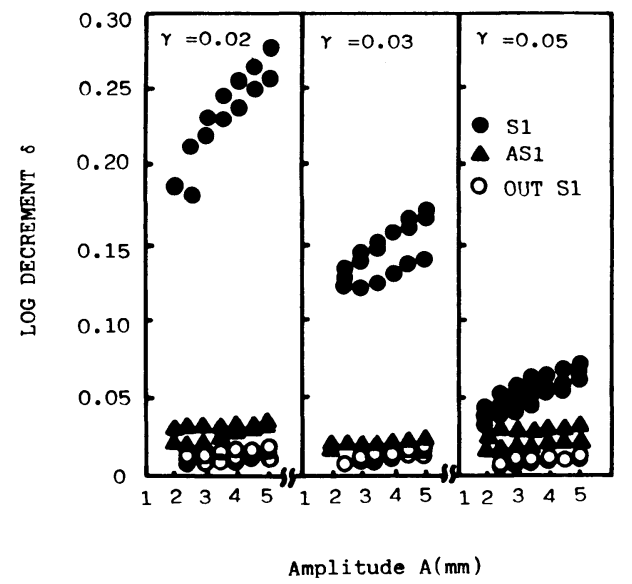

Fig. 6 Dependence of modal damping upon amplitude $($ CABLE $2, l=2.05 \mathrm{~m})$.

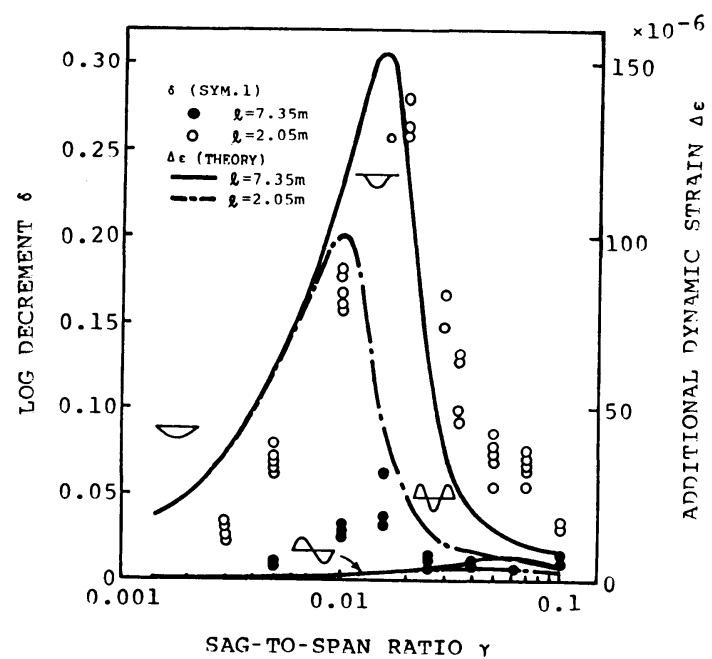

Fig. 7 Comparison of log decrement with additional dynamic strain (CABLE 2). 


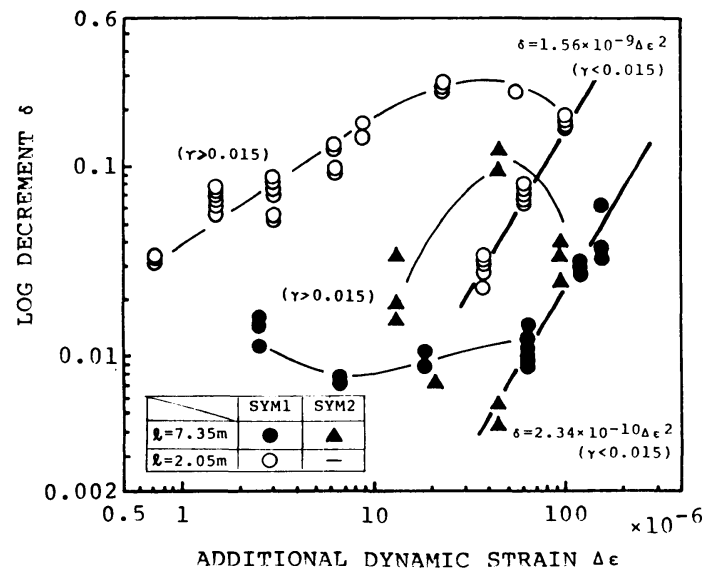

Fig. 8 Log decrement versus additional dynamic strain (CABLE 2, S 1).

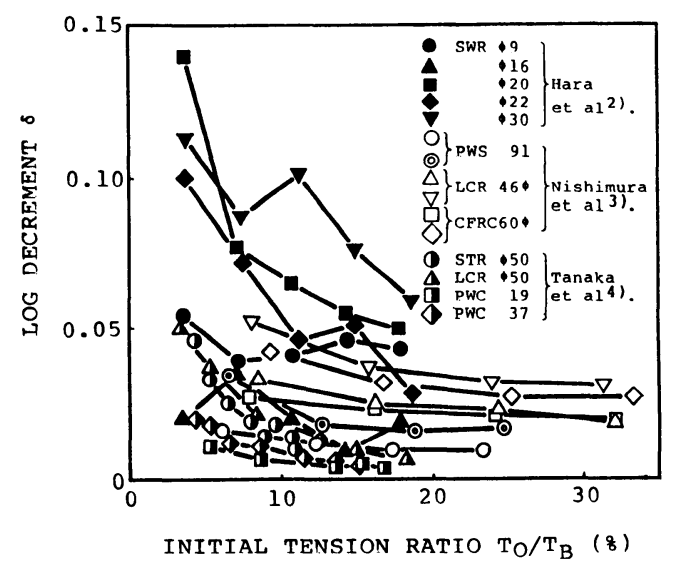

Fig. 9 Log decrement versus initial tension ${ }^{2) \sim 4)}$

for the fact that the modal dampings of asymmetric mode and out-of-plane mode are small.

The relation between modal damping and dynamic strain is shown more directly in Fig. 8 where the abscissa is the additional dynamic strain and the ordinate is the log decrement both on log scales. The data points plotted lie almost in a straight line of slope 2 in case of the sag-to-span ratios less than the modal crossover point $(\gamma<0.015)$. This means that the modal damping is in proportion to the square of dynamic strain, i. e., the hysteresis energy. The straight line in the figure, however, is different for different span length even for the same cable, and the modal dampings for longer span length is smaller. This is due to the effect of initial tension of cable as is discussed in the next section. As can be also seen in Fig. 8, the correspondence of $\delta$ to $\Delta \varepsilon^{2}$ is poor for large sag-to-span ratios $(\gamma>0.015)$, suggesting that the hysteresis energy is not necessarily proportional to $\Delta \varepsilon^{2}$ for flexural oscillation. Accuracy in the evaluation of $\Delta \varepsilon$ for large-sagged cables remains a possible cause of the poor agreement.

\section{(4) Dependence of modal damping on initial tension ...... effects of span length}

The effects of initial tension on the first modal damping have been reported in the past experimental studies ${ }^{2)}$ ) on damping of wire ropes. Those experimental data are arranged in one graph with the abscissa of initial tension $T_{0}$ nondimensionalized by tensile strength $T_{B}$ (Fig.9). In Fig.9, the log decrements are greatly changed up to $T_{0} / T_{B}$ of the order of $10 \%$ and are larger for lower initial tension, while the log decrements are almost constant when the initial tension is introduced to a certain degree, for example $20 \%$ of $T_{0} / T_{B}$ or more. This may be considered to mean that the frictional force between wires which compose a cable is changed with the initial tension, and that the friction decreases for the higher initial tension because the relative movement of each wire is restricted under such a condition.

Fig. 10 shows the plots of the present experimental results on a log-log graph paper for the asymmetric and out-of-plane modes which are not affected very much by the additional dynamic strain. As can be seen from Fig. 10, $T_{0} / T_{B}$ is under $10 \%$ in the present experiment, and each modal damping is changed equally with the initial tension regardless of the span length and the mode. That is the modal damping becomes small for longer spanned cable because of high initial tension. The differences in the first symmetric modal dampings for different span length, shown in Fig. 8, can be considered to be due to this fact.

\section{(5) Effects of tensile rigidity}

For the model cable of small tensile rigidity (CABLE 1), the changes of modal dampings and additional dynamic strains are shown in Fig. 11 with respect to the sag-to-span ratio. The corresponding natural frequencies are indicated as solid line in Fig. 2. The first symmetric modal dampings and additional dynamic strains, as is the same as $\mathrm{CABLE} 2$, are very large in the modal transition region, especially for 


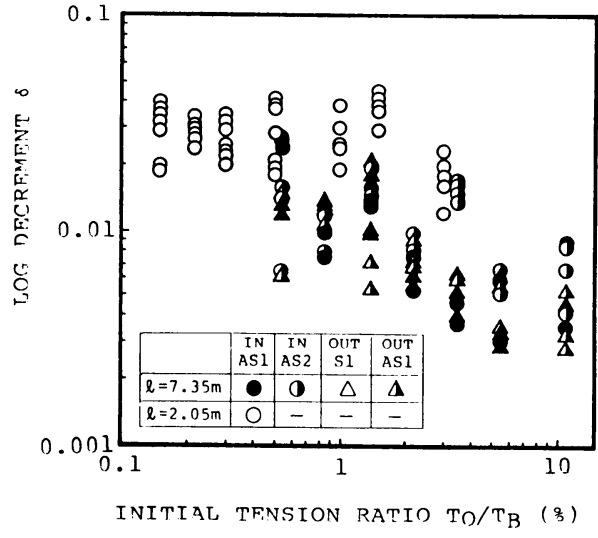

Fig. 10 Log decrement versus initial tension (CABLE 2).

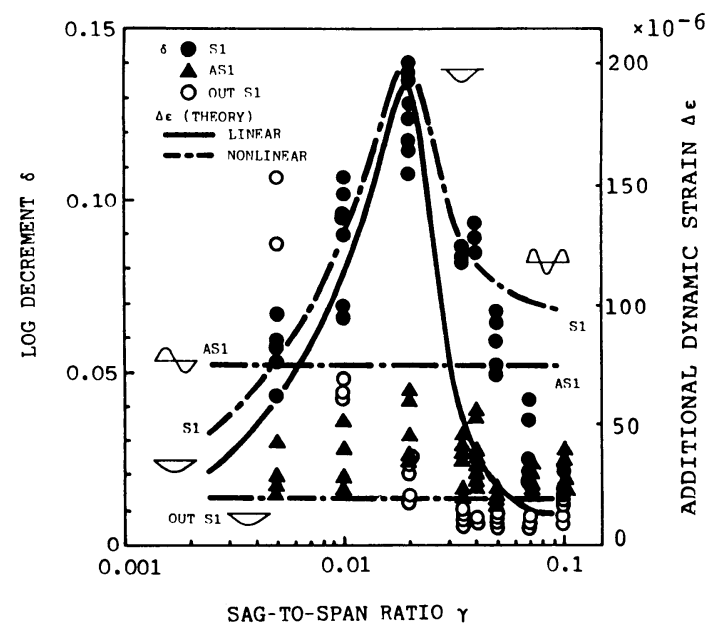

Fig. 11 Comparison of log decrement with additional dynamic strain (CABLE 1).

the sag-to-span ratio around the modal crossover point. Fig. 12 shows the relation between the log decrement and the additional dynamic strain for CABLE 1. It is evident from Fig. 12 that $\delta$ is not proportional to $\Delta \varepsilon^{2}$ unlike CABLE 2, while there is some functional relation between $\delta$ and $\Delta \varepsilon$. Therefore we calculated dynamic strains by Eq. (4); the nonlinear evaluation of dynamic strain was made. The chain line in Fig. 11 and the symbol $\bigcirc$ in Fig. 12 represent the calculated nonlinear dynamic strains. In Fig. 11, the effect of nonlinearity is significant for the symmetric modes of large sagged cable, and for the asymmetric and out-of-plane modes without regard to the sag-to-span ratio. The correspondence of $\Delta \varepsilon$ to the modal dampings seems to be better when the dynamic strain evaluated by the nonlinear equation is used. In fact, the log decrement $\delta$ is becoming proportional to the square of nonlinear dynamic strain $\Delta \varepsilon^{2}$ in Fig. 12. No general conclusion on this point, however, has been reached till now because the accuracy of the nonlinear dynamic strain calculated is uncertain and has not been examined.

\section{(6) Effects of chord inclination}

For the inclined cable of $\theta=30^{\circ}$, the plots of natural frequency versus sag-to-span ratio are shown in Fig. 13, and the comparison between modal dampings and additional dynamic strains is presented in Fig. 14 . The in-plane symmetric mode changes into the higher asymmetric mode and the asymmetric mode into the higher symmetric mode for the inclined cable when the sag-to-span ratio becomes larger ${ }^{11)}$ (Fig. 13). The modal dampings are again large in this modal transition region (Fig. 14) but the tendency is somewhat

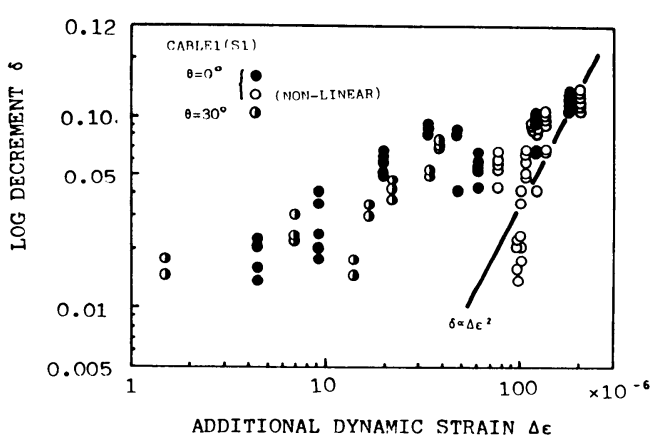

Fig. 12 Log decrement versus additional dynamic strain (CABLE 1, S 1).

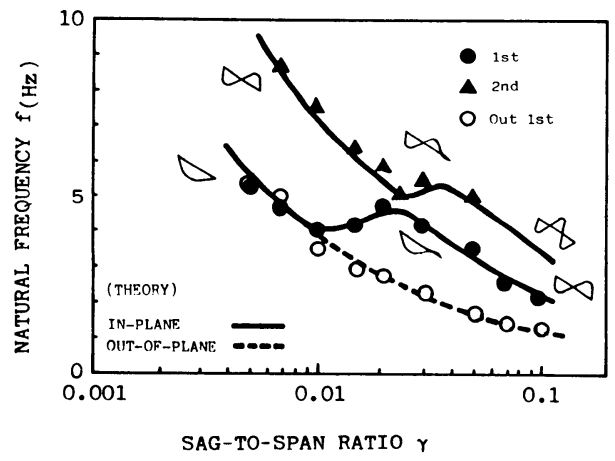

Fig. 13 Natural frequency versus sag-to-span ratio in inclined cable $\left(\theta=30^{\circ}\right)$. 


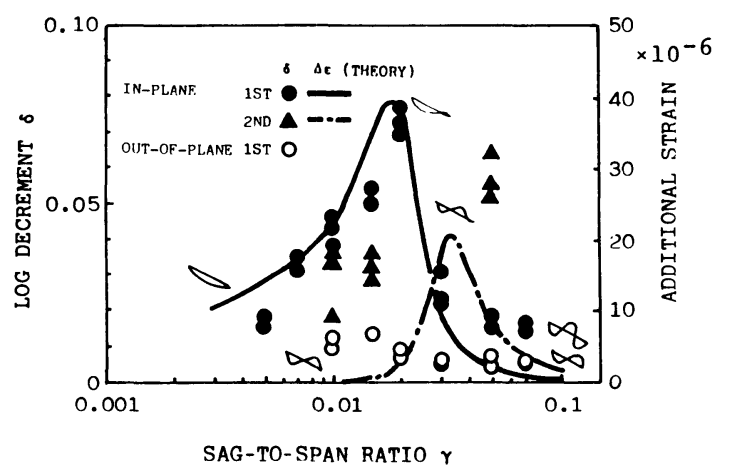

Fig. 14 Comparison of $\log$ decrement with additional dynamic strain in inclined cable $\left(\theta=30^{\circ}\right)$.

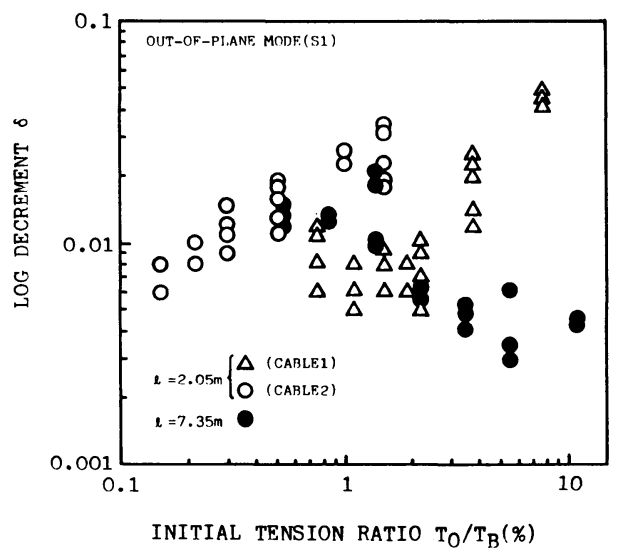

Fig. 15 Log decrement versus initial tension (Out-of-plane mode)

different from that for the horizontally suspended cable; even in the modal transition region, the modal dampings decrease rapidly when the normal mode approaches the asymmetric mode, while the dampings for the pseudo-symmetric mode are still large. Changes of modal damping and dynamic strain with respect to the sag-to-span ratio, however, correspond to each very well also for the inclined cable, and the modal dampings of cable can be again explained by the hysteresis energy (Fig. 12 and Fig. 14).

(7) Energy dissipation from support

Fig. 15 shows the change of log decrement with the initial tension for the out-of-plane first symmetric mode. As can be seen from Fig. 15, the trend is different for each span length; for the long span cable of $l$ $=7.35 \mathrm{~m}$, the modal damping decreases when the initial tension increases as is the same as before (4. (4)), whereas the damping increases for the short span cable of $l=2.05 \mathrm{~m}$. It is supposed that the model cable of high initial tension slipped transversely at the support where the cable was only wound around the bar steel, and this can be considered the reason why the damping increases with higher initial tension. In any case the energy dissipation from support has a chance to give large effects on the modal damping. Further study on this problem must be conducted in future.

\section{CONCLUDING REMARKS}

The logarithmic decrements of flexural oscillation of suspended cables was measured through the free oscillation experiment with model cables. The dynamic analysis for free oscillation was also made by the finite element method in order to investigate natural frequencies, normal modes and additional dynamic strains, and then the characteristics of modal dampings of cable were discussed. The brief conclusions obtained through this study are as follows:

(1) The modal dampings of in-plane symmetric modes are larger than other modal dampings in the modal transition region. Especially for the sag-to-span ratio around the modal crossover point, the in-plane symmetric modal dampings have a peak.

(2) The modal dampings of cable are closely related to the additional dynamic strains of normal mode and the primary cause of modal damping is the internal damping due to the hysteresis energy of cable.

(3) The damping of cable is also affected by the initial tension because the cable is an aggregate of wires. The modal dampings are larger for lower initial tension but almost independent on the initial tension when the initial tension exceeds a certain level.

(4) The modal dampings are smaller for longer span cable for the same sag ratio. This is partly caused by the effect of initial tension.

(5) For the inclined cable, the characteristics of modal dampings are somewhat different from those 
for the horizontally suspended cable because of the different property of mode transition.

(6) The damping of the in-plane symmtric modes depends on the amplitude of oscillation; smaller modal damping was observed for smaller amplitude. This amplitude dependence is remarkable around the modal crossover point. On the other hand, dampings of the asymmetric and out-of-plane modes are very small and hardly depend upon the amplitude.

The characteristics of modal dampings of suspended cables with fixed supports have been demonstrated in this paper. Cable used as a structural member, however, is usually supported elastically, so that further study on the effects of support must be conducted.

\section{ACKNOWLEDGMENT}

The authors owe the experiment in the present paper to K. Shimogiku, S. Sakai and T. Mizumura, all former students of Department of Foundation Engineering, Saitama University. Cordial thanks are also extended to K. Ishikawa and T. Yokobayashi, technicians of Saitama University, for their assistance for drawing. Financial support by the Ministry of Education, Science and Culture, Japan under Grant-in-Aid for Scientific Research is also gratefully acknowledged.

\section{REFERENCES}

1) Ito, M. and Katayama, T. : Damping of bridge structures, Proc. of JSCE, Vol. 117, pp. 12-22, May 1965 (in Japanese).

2) Hara, M. and Ueda, K. : Study on damping of wire ropes, Proc. of 21 th Annual Conference of JSCE, I-37, pp. 37-1-2, 1966 (in Japanese).

3) Nishimura, H., Hironaka, K and Shinke, T. : Experimental study on characteristics of rope oscillation, Proc. of 32 nd Annual Conference of JSCE, I-177, pp. 334-335, 1977 (in Japanese).

4) Tanaka, Y., Tamai, K. and Haraguchi, T. : On damping of inclined cable, Proc. of 40 th Annual Conference of JSCE, I-263, pp. 525-526, 1985 (in Japanese).

5) Tsuji, M. and Kanou, I. : Damping of wire ropes, Proc. of 13 th Annual Conference of Construction Consultant Association, pp. 73-86, Aug. 1980 (in Japanese).

6) Ramberg, S.E. and Griffin, O.M. : Free vibrations of taut and slack marine cables, Proc. of ASCE, Vol. 103, No. ST 11, pp. 2079-2092, Nov. 1977.

7) Ito, M. , Fujino, $\mathrm{Y}$ and Yamaguchi, H. : Wind tunnel study on galloping oscillations of suspended figure-8 telecommunication cables, Proc. of JSCE, Structural Eng./Earthquake Eng., Vol.2, No. 1, pp. 193 s-201 s, April 1985.

8) Tsukuba Construction Engineering Office, Nippon Telegram and Telephone Authority: Table on damping of figure-8 telecommunication cables (unpublished), 1979 (in Japanese).

9) Maeda, Y., Maeda, K. and Echigo, S. : System damping of cable-stayed girder bridges, Proc. of JSCE, No. 333, pp. 35-45, May 1983 (in Japanese).

10) Yamaguchi, H., Miyata, T. and Ito, M. : Time response analysis of a cable under harmonic excitation, Proc. of JSCE, No. 308 , pp. 37-45, April 1981 (in Japanese).

11) Yamaguchi, H. and Ito, M. : Linear theory of free vibrations of an inclined cable in three dimensions, Proc. of JSCE, No. 286 , pp. 29-36, June 1979 (in Japanese).

12) Kotsubo, S., Takanishi, T., Ijima, K. and Sonoda, T. : Frequency characteristics of spring constants of a suspended transmission line, Proc. of JSCE, No.344 I-1, pp. 225-234, April 1984 (in Japanese).

13) Henghold, W.M. and Russell, J. J. : Equilibrium and natural frequencies of cable structures (a nonlinear finite element approach), Computers \& Structures, Vol.6, pp.267-271, 1976.

(Received April 21 1987) 